\title{
Fabrication, Mechanical and Dielectric Characterization of 3D Orthogonal Woven Basalt Reinforced Thermoplastic Polyimide Composites
}

\author{
Shuna Hou, Jianfei Xie, Ye Kuang, Xianhong Zheng, Lan Yao*, Yiping Qiu \\ Key Laboratory of Textile Science and Technology, Ministry of Education, College of Textiles, \\ Donghua University, Shanghai, China \\ Email: *yaolan@dhu.edu.cn
}

Received 2 February 2015; accepted 8 April 2015; published 15 April 2015

Copyright (C) 2015 by authors and Scientific Research Publishing Inc.

This work is licensed under the Creative Commons Attribution International License (CC BY). http://creativecommons.org/licenses/by/4.0/

\section{(c) (i) Open Access}

\section{Abstract}

The 3D orthogonal woven basalt fiber reinforced polyimide (PI) composites were fabricated and characterized in this study. The PI film was firstly prepared to determine PI processing parameters. Fourier transform infrared (FTIR) analysis showed that $300^{\circ} \mathrm{C}$ was the suitable imidization temperature. Thermal gravimetric analysis (TGA) and differential scanning calorimetry (DSC) results showed relatively good thermal properties of the PI film. In the fabrication of composites, the multi-step impregnation method was applied. The bending properties of $3 \mathrm{~mm}$-thick composite showed increasing trend in all and the second-time impregnated composite had much higher value than the first-time impregnated composite. Moreover, the bending fracture mode photos showed obvious creases except for the first-time impregnated materials, which agreed well with the bending property values. The dielectric constants for the composites were complex because they had not regular value following the mixing rule of the composites, which was mainly due to the interfacial polarization and other effects in the fabrication processing.

\section{Keywords}

3D Orthogonal Woven Structure, Basalt Fiber, Thermoplastic Polyimide, Bending Properties, Dielectric Properties

\footnotetext{
${ }^{*}$ Corresponding author.

How to cite this paper: Hou, S.N., Xie, J.F., Kuang, Y., Zheng, X.H., Yao, L. and Qiu, Y.P. (2015) Fabrication, Mechanical and Dielectric Characterization of 3D Orthogonal Woven Basalt Reinforced Thermoplastic Polyimide Composites. Journal of Textile Science and Technology, 1, 35-44. http://dx.doi.org/10.4236/jtst.2015.11005
} 


\section{Introduction}

For recent years, much attention has been given to polyimide (PI) and its composites due to their high mechanical strength, good thermal stability, high stability under vacuum, good anti-radiation, and good solvent resistance. Investigations on the fiber reinforced thermoplastic polyimide composites have been made by many researchers [1]-[7]. In [3], the effect of rare earth (RE) solution surface modification of poly-p-phenylenebenzobisoxazole (PBO) fibers on the tensile property of PBO fiber-reinforced thermoplastic polyimide (PBO/PI) composites have been investigated. Experimental results revealed that RE surface treatment could effectively improve the interfacial adhesion between PBO fibers and PI matrix. In [5], they compared the effects of rare earth solution (RES) treatment and air oxidation surface treatment on the mechanical and tribological properties of carbon fiber-reinforced polyimide composites and found that the RES surface treatment was superior to air oxidation treatment in promoting interfacial adhesion between carbon fiber and PI matrix. Paplham et al. [6] have investigated the effect of crystallization of the thermoplastic polyimide upon the microhardness values of the resin. The results showed that the addition of carbon fibers to the neat resins greatly increased the microhardness and thus the yield stress of the composite.

The emergence of 3D woven composites is aimed to improve the weaknesses of traditional laminated structures, namely delamination. Among the different technologies to produce 3D fiber architecture, 3D orthogonal woven preforms have gained industrial acceptance [8]-[15]. However, little has been reported on the properties of $3 \mathrm{D}$ fiber reinforced thermoplastic polyimide composites though the 3D composites have been more and more frequently used because of their damage tolerance and anti-delamination properties.

In this study, 3D basalt fiber reinforced PI composites have been fabricated. The selection of basalt fibers is due to its desirable properties such as high tensile strength, high tensile modulus, and excellent heat resistance. It is produced in a similar way as glass fibers using basalt rock which is an over-ground, effusive volcanic rock with $45 \%$ - 52\% $\mathrm{SiO}_{2}$ [16]-[18]. The whole paper was arranged as follows. The thermoplastic PI film was firstly prepared by imidization process of polyamic acid. Then the measurements on the film including surface chemical analysis and thermal property analysis were investigated. Finally, the 3D composite materials were fabricated and the bending properties as well as the dielectric properties were characterized and discussed.

\section{Experimental}

\subsection{Preparation of Polyamic Acid (PAA) and PI Film}

The polyimide was obtained through the imidization process of the PAA. The PAA was synthesized by reacting 3,3', 4,4'-benzophenonetetracarboxylic dianhydride (BTDA) with 4,4-oxydianiline (4,4-ODA) .The molar fraction of them was 1.02:1. The N, N-dimethyl formamide (DMF) was used as the solvent of 4,4'-ODA. Figure 1 shows the synthesis process of PAA and PI. The PAA film was cast onto a clean glass, where thickness was controlled by the diameter of copper wire around glass rod. The PAA film was imidized according to the procedure in a FIR radiation oven as shown in Figure 2. The final yellow imidized film was peeled off the glass plate by soaking in hot water and dried in the oven.

\subsection{Characterization of the PI Film}

Fourier transform infrared (FTIR) spectra obtained on a Nicolet 5700 ConTinu $\mu \mathrm{m}$ Fourier Transform Infrared Microscopy was used to analyze the surface chemical properties of PI films imidized at different temperatures. Thermal gravimetric analysis (TGA) was performed on a Shimadzu DT-40 thermal analysis system at a heating rate of $10^{\circ} \mathrm{C} \cdot \mathrm{min}^{-1}$ in a nitrogen atmosphere at a flow rate of $20 \mathrm{~cm}^{3} \cdot \mathrm{min}^{-1}$. Dfferential scanning calorimetry (DSC) was performed on a Perkin Elmer Pyris 1 DSC Differential Scanning Calorimeter in a nitrogen atmosphere at a flow rate of $50 \mathrm{~cm}^{3} \cdot \mathrm{min}^{-1}$. The glass transition temperature $\left(\mathrm{T}_{\mathrm{g}}\right)$ was determined by the inflection point of the heat flow versus temperature curve.

\subsection{Composite Manufacturing}

In the manufacturing process of the composite, the multi-step impregnation method was applied. In the first-time impregnation, the 3D orthogonal woven basalt fabric was immersed into the PAA, and then was put into the vacuum oven to remove the air bubbles. Padding was also necessary to remove the superfluous liquid on the fabric. 
<smiles>O=C(c1ccc2c(c1)C(=O)CC2=O)c1ccc2c(c1)C(=O)OC2=O</smiles><smiles>Nc1ccc(Oc2ccc(N)cc2)cc1</smiles>

ODA

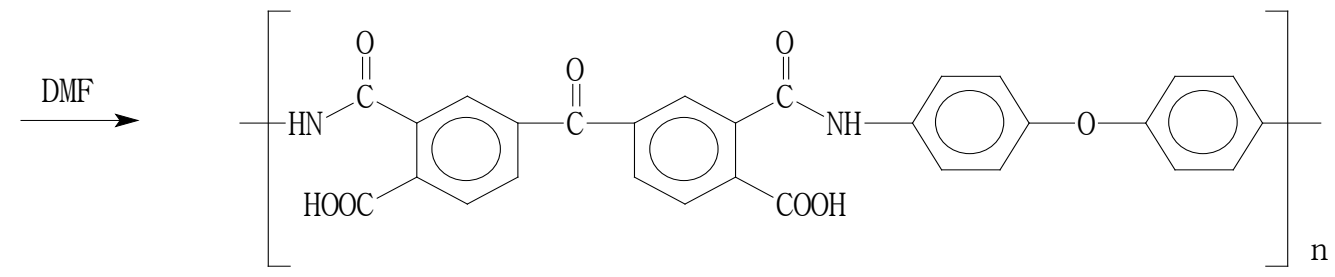

Polyamide acid<smiles>Cc1ccc(Oc2ccc(N3C(=O)c4ccc(C(=O)c5ccc6c(c5)C(=O)N(C)C6(C)[14CH3])cc4C3=O)cc2)cc1</smiles>

Polyimide

Figure 1. The synthesis process of PAA and PI.
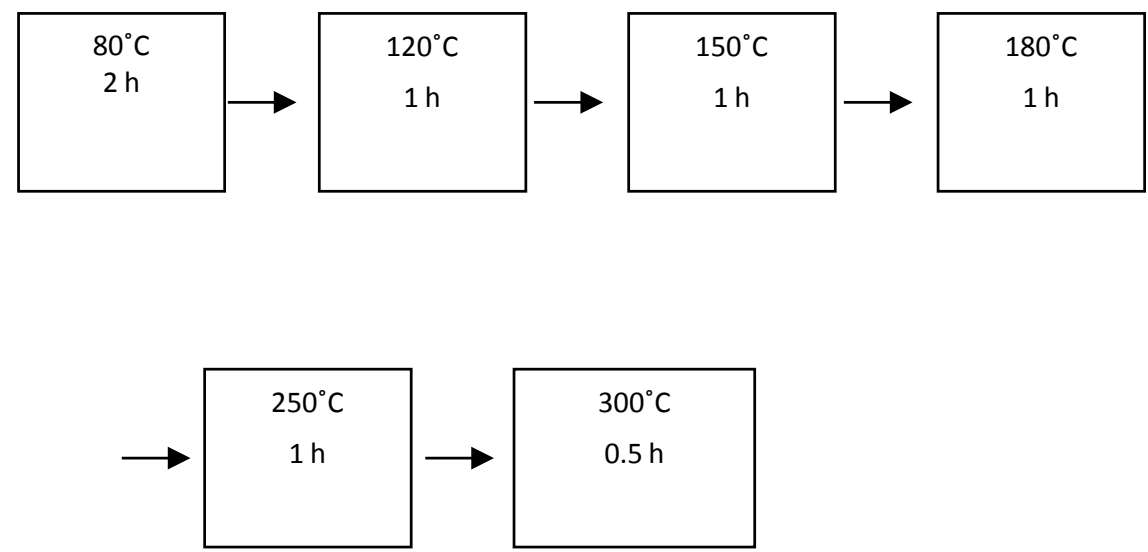

Figure 2. The processing of thermal imidization.

Under the pressure of 0.08 - 0.09 MPa, the 3D fabric was dried and pre-imidized at 80/1 h, 120/1 h, 150/1 h and $180 / 1 \mathrm{~h}$. In the second-time impregnation process, the first-time prepregs were immersed into the PAA and being treated following the same process as the first-time impregnation. Thus impregnation for five times was performed totally and after each impregnation, the samples were saved and the resin content was calculated. In the very final step, the prepregs were molded into composites using the press vulcanizer at the following sequence shown in Figure 3. After cooled to the room temperature, the five compact 3D orthogonal woven basalt /PI composites were obtained. The $3 \mathrm{~mm}$ and $5 \mathrm{~mm}$ thickness of composite were fabricated finally. For convenience, the composite samples of $3 \mathrm{~mm}$ thickness were named as S1, S2, S3, S4 and S5, representing one to five times of impregnation respectively. Using the 3D orthogonal woven structure fabric as the preform, the molding method applied in this study was new and totally different with other PI composites processing methods [2]. 


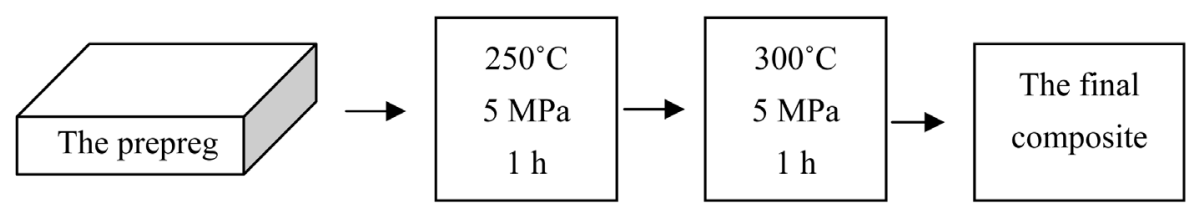

Figure 3. The post-impregnation process for the final composite panels.

\subsection{The Photographs}

To observe different appearances of the prepregs for different times of impregnation, the microscopic photos were taken using the KH-1000 3D digital video microscopic measurement system.

\subsection{Bending Test}

The 3-point bending tests were conducted using WDW-20 Computerized Electronic Universal Testing Machine on regular specimens of $250 \times 25 \mathrm{~mm}$, with the span length fixed at $150 \mathrm{~mm}$. The specimens were cut with the length being in the directions of the warp and weft yarns. The specimens were deflected until rupture occurred in the outer fiber. The failure modes for the 3-point bending test of the composites were analyzed using the manual camera.

\subsection{Dielectric Property Test}

The dielectric property tests were performed on Agilent 4291 B $1.8 \mathrm{GHz}$ Impedance/Material Analyzer. All the specimens were dried before measuring. The dielectric constant and loss tangent of the composites were obtained in the frequency range from $1 \mathrm{MHz}$ to $1000 \mathrm{MHz}$.

\section{Results and Discussion}

\subsection{The Properties of PI Films}

FTIR of the PI films at different imidization temperatures are shown in Figure 4. We have calculated the ratio of the absorbance at 1720 or $1380 \mathrm{~cm}^{-1}$ to that at $1500 \mathrm{~cm}^{-1}$, that is $\mathrm{C}=\mathrm{O} / \mathrm{C}=\mathrm{C}$ or $\mathrm{C}-\mathrm{N} / \mathrm{C}=\mathrm{C}$. The changing trend of the ratios versus the imidization temperature can be used to characterize the imidization process indirectly (shown in Figure 5). It can be seen that the imidization degree had the increasing trend with increasing temperature in all. At $300^{\circ} \mathrm{C}$, the imidization degree of the PI film reached almost the maximum value. Therefore, $300^{\circ} \mathrm{C}$ was used determined as the final imidization temperature of PI films.

Figure 6 and Figure 7 show DSC and TGA curves of the PI film imidized at $300^{\circ} \mathrm{C}$. The PI film had $\mathrm{T}_{\mathrm{g}}$ of $261.87^{\circ} \mathrm{C}$ and decomposed temperature of $531.0^{\circ} \mathrm{C}$ in the nitrogen, indicating the adequate thermal properties of the film.

\subsection{The Resin Content of the Composites}

Figure 8 shows the resin content versus times of impregnation. The resin content increased as the times were increased for the fabrics of 3 and $5 \mathrm{~mm}$ thickness. The $3 \mathrm{~mm}$-thick composite had higher resin content compared with the 5-mm thick composite at each-time impregnation. The lower thickness made the resin easier infuse into the fabric under the same processing parameters. After five-time impregnation, the $3 \mathrm{~mm}$-thick composite had $33.61 \%$ resin content which was much higher than that of 5 mm-thick composite (18.30\%).

\subsection{Bending Test}

Table 1 lists the bending properties of the $3 \mathrm{~mm}$-thick composite. In all, the bending strength and modulus increased as the resin content was increased, which was mainly due to the improved face properties of the composite as the PI resin was infused. It is also noticed that composites showed significantly better bending properties after the second impregnation processing was finished indicating the positive effect of multi-step impregnation processing. In addition, the bending properties in the weft direction were higher than those in the warp direction due to the higher volume fraction of the weft yarns. 


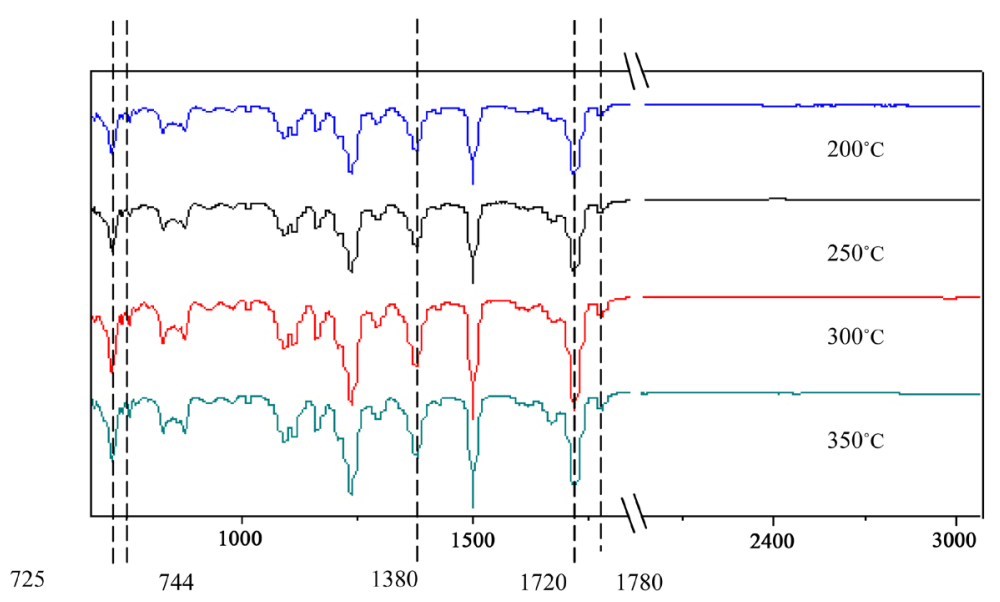

Figure 4. FTIR of PI films at different temperatures.

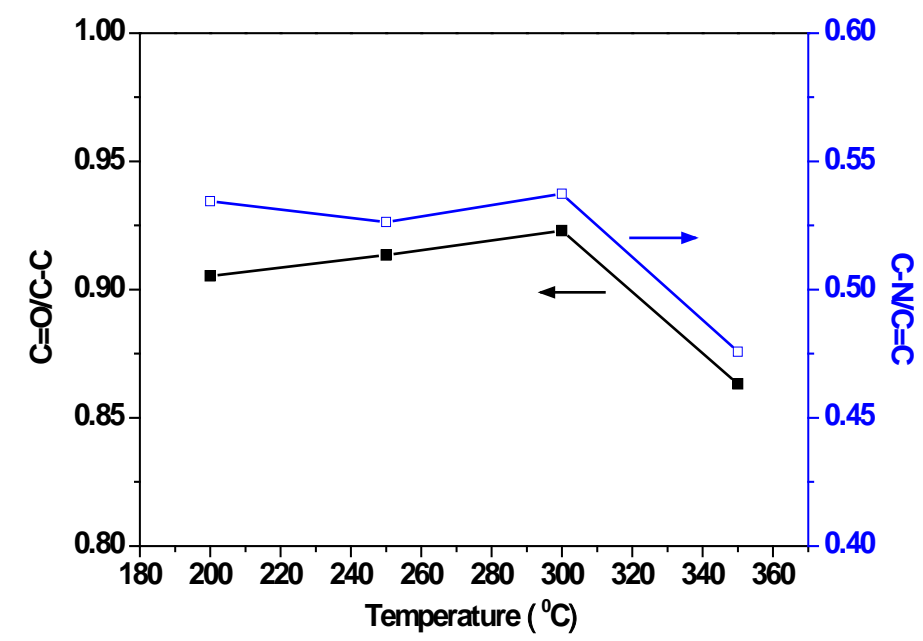

Figure 5. Effect of temperature on imidization degree of PI.

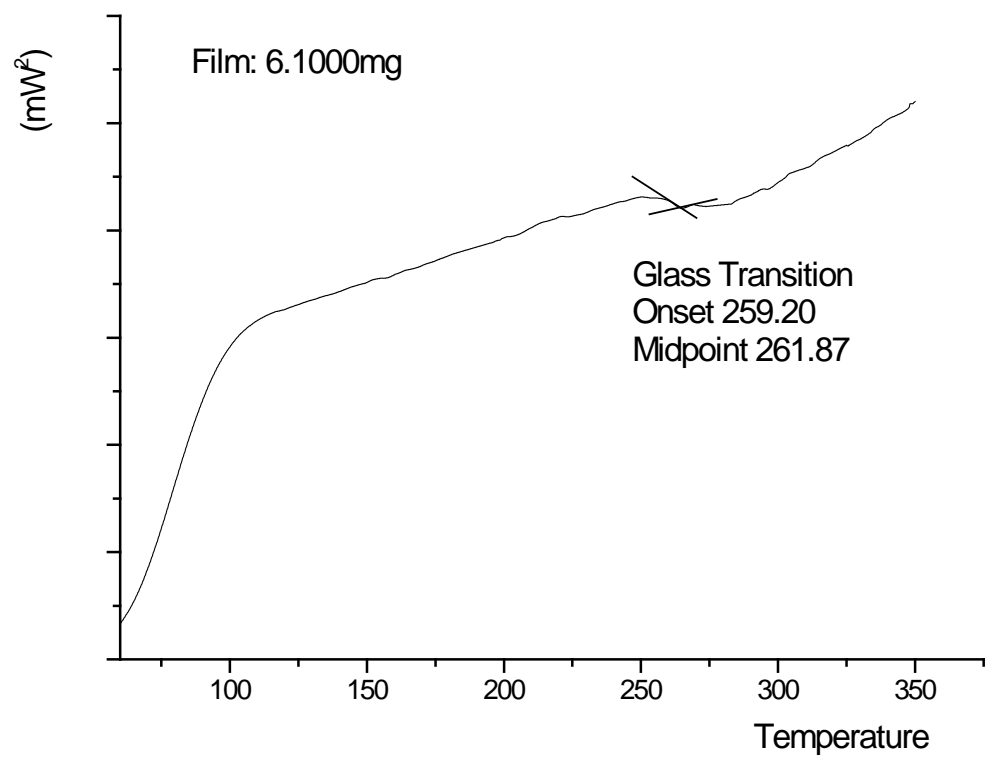

Figure 6. DSC curve of PI film imidized at 300 degree. 


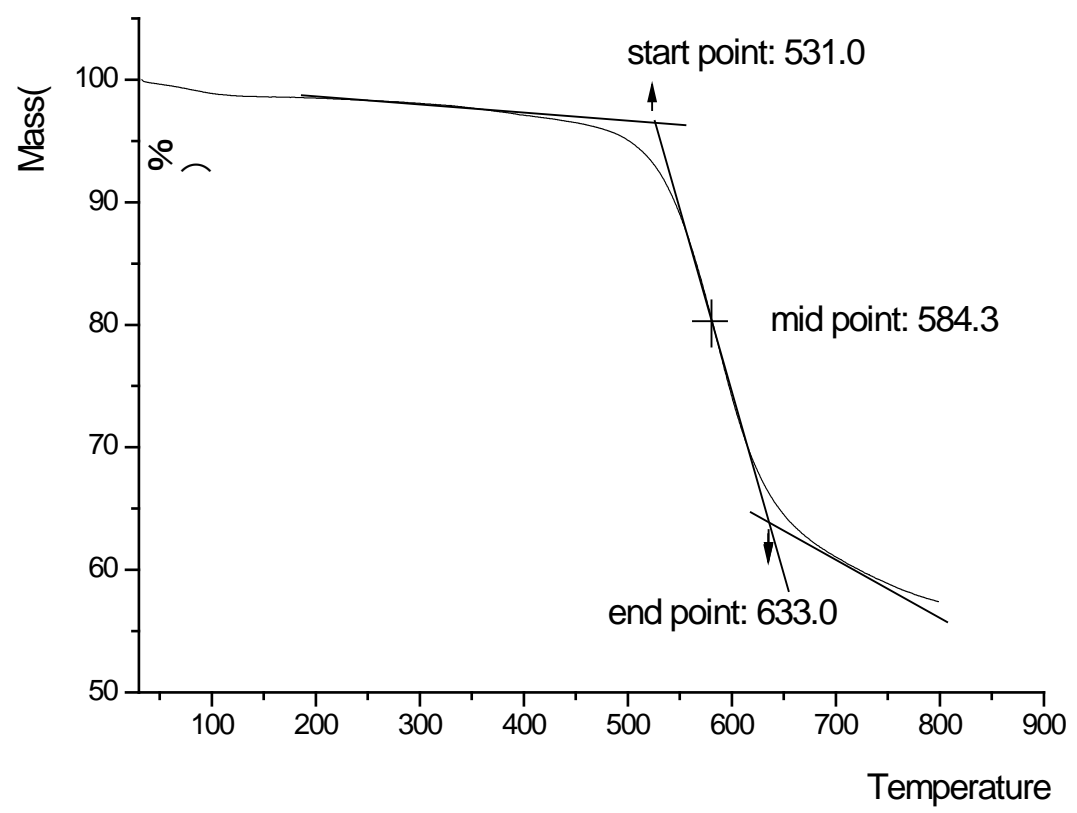

Figure 7. TGA curve of the PI film imidized at 300 degree.

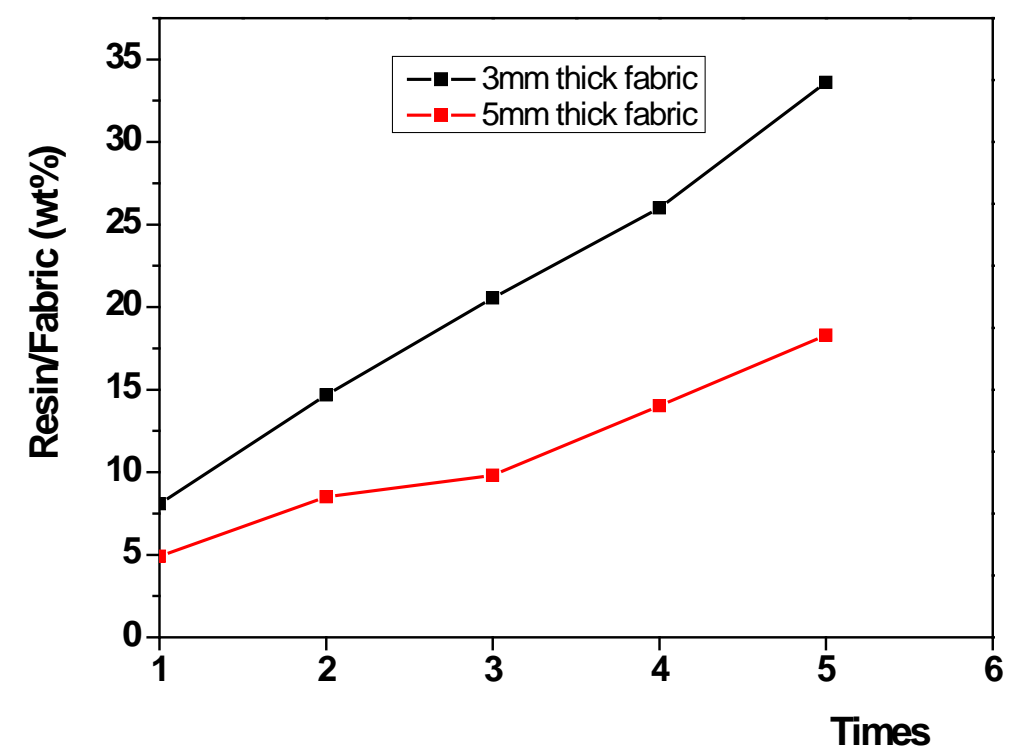

Figure 8. The resin content of the composites.

Table 1. The bending properties of the composite with different times of impregnation.

\begin{tabular}{ccccc}
\hline \multirow{2}{*}{ Samples } & \multicolumn{2}{c}{ Bending strength (MPa) } & \multicolumn{2}{c}{ Bending modulus (GPa) } \\
\cline { 2 - 5 } & Warp direction & Weft direction & Warp direction & Weft direction \\
\hline S1 & 57.20 & 65.53 & 1.98 & 6.72 \\
S2 & 179.77 & 161.54 & 7.96 & 13.26 \\
S3 & 168.32 & 190.02 & 8.96 & 14.10 \\
S4 & 183.76 & 214.97 & 8.73 & 13.83 \\
S5 & 214.14 & 236.24 & 8.16 & 14.49 \\
\hline
\end{tabular}


Figure 9 shows the bending failure modes of the composite materials. It can be seen that all the materials had creases after the bending damage expect for the one-time impregnated material which had the lowest resin content. These damage modes illustrated the bending properties and agreed with the bending properties in Table 1.

\subsection{Dielectric Properties}

Frequency dependence of dielectric constant and dielectric loss are shown in Figure 10 and Figure 11. For each type of the composites, the dielectric constant remained relatively constant but a little decrease as the frequency was increased indicating dielectric stability under frequencies of the PI composites. In addition, the resin content of the five composites were decreasing in the order S5 $>$ S4 $>$ S3 $>$ S2 $>$ S1, however, the dielectric constant for them are found to be decreasing in the order S3 $>$ S2 $>$ S5 $>$ S4 $>$ S1. This does not agree with the well-known mixing rule for dielectric constant of a multi-component material. Similar results have been reported in our previous study, in which the dielectric constants of the five aramid/glass hybrid composite structures were found not to be in the order of the fiber content [19]. The dielectric losses of the five composites were very close in Figure 11 and showed constant value as the frequency was increased.

\section{Discussions}

The photos in Figure 12 and Figure 13 show the typical surface and inner images of the $3 \mathrm{~mm}$ and $5 \mathrm{~mm}$ thick composites. It has been mentioned that the surface resin content increased as the times were increased; however, it was not the case for the inner part of the composites. When the temperature was raised, the solvent evaporating leaded to the viscosity rising with a film forming at the outer surface of the composite. The film hindered the inner solvent evaporating outwards and thus air bubbles were produced. Due to the lower thickness, the $3 \mathrm{~mm}$ thick composite had some yellow polyimide resin in the inner part. However, for the $5 \mathrm{~mm}$ thick composite, relatively less polyimide could be observed.

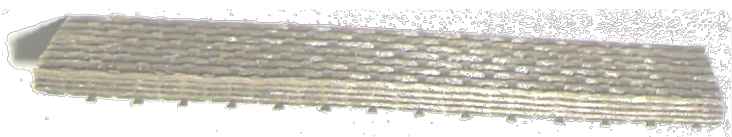

(a)

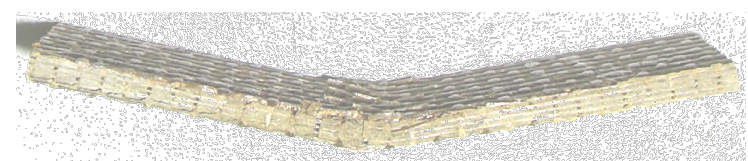

(b)

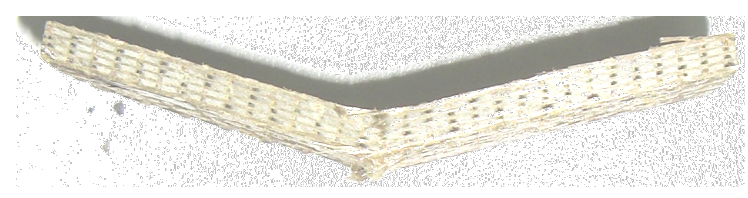

(c)

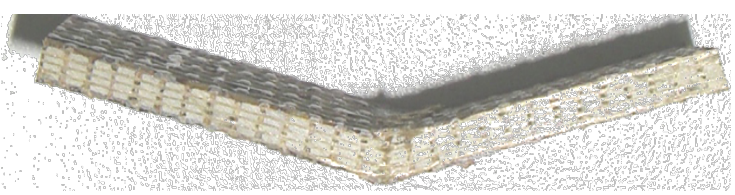

(d)

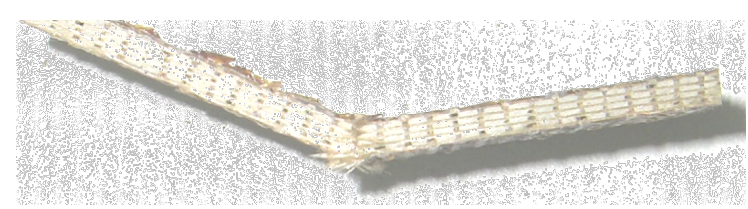

(e)

Figure 9. The bending failure modes of (a) S1 - (e) S5. 


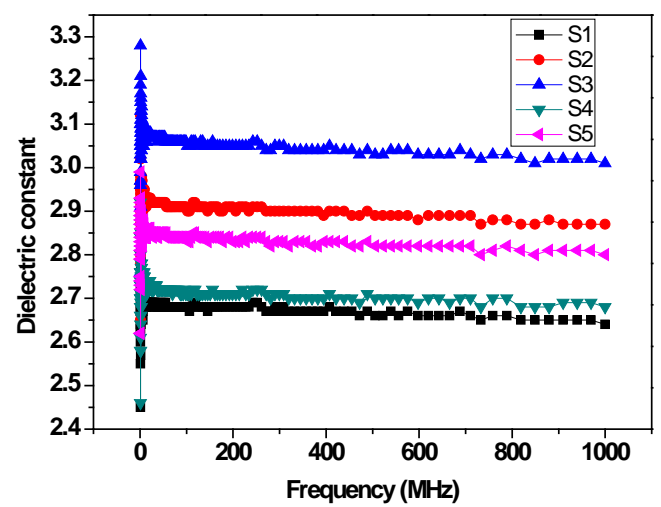

Figure 10. Frequency dependence of dielectric constant of the composites.

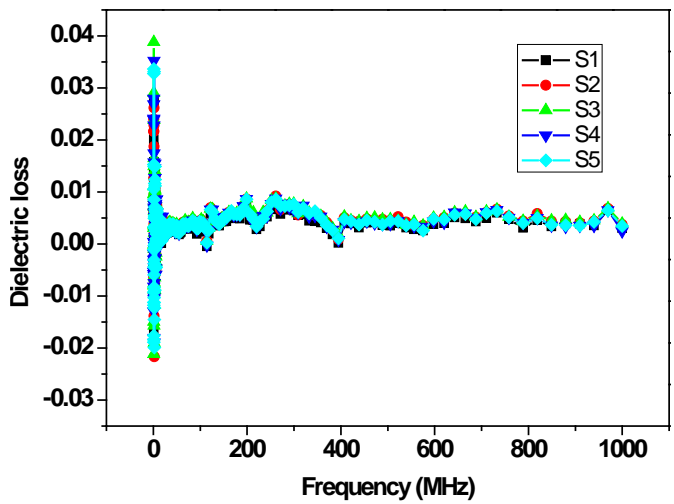

Figure 11. Frequency dependence of dielectric loss of the composites.

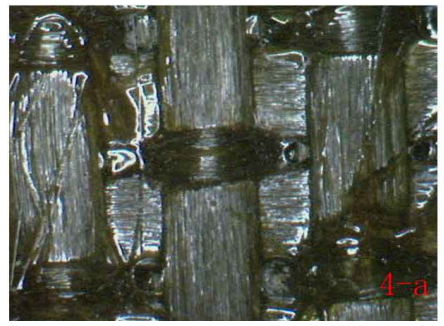

(a)

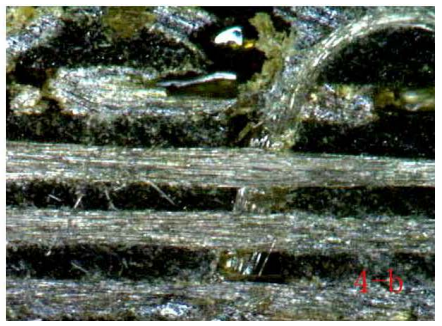

(b)

Figure 12. Typical images for (a) the outer surface and (b) the inner section of four-time impregnated composite with $3 \mathrm{~mm}$ thickness.

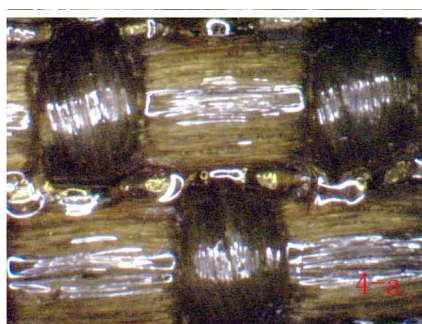

(a)

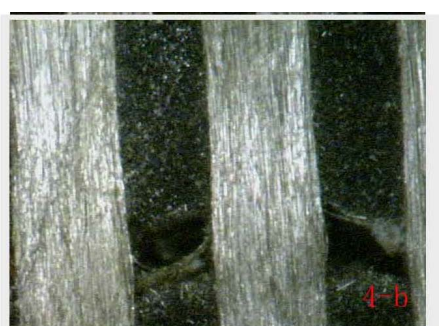

(b)

Figure 13. Typical images for (a) the outer surface and (b) the inner section of four-time impregnated composite with $5 \mathrm{~mm}$ thickness. 
Dielectric constant is relatively a complex value in the composites, which is related to the material component, volume fraction, manufacturing method and other effects. In this study, the phenomenon of not agreeing with the mixing rule was mainly due to the existence of interface polarization between fiber and resin, which made the final dielectric constant complicated. For further studies, interface polarization of the basalt fiber and PI needs to be investigated to find the influence rule.

\section{Conclusion}

The PI film was firstly prepared to obtain the imidization temperature for the thermoplastic polyimide. To fabricate the 3D orthogonal woven basalt PI composite, the multi-step impregnation method was applied. After fivetime impregnation, the $3 \mathrm{~mm}$ and $5 \mathrm{~mm}$ thick composites had 33.61\% and 18.30\% resin content respectively indicating that the lower thickness was easier for the resin to infuse. In the bending test for $3 \mathrm{~mm}$-thick composite, the bending strength and modulus increased as the resin content was increased and the significant increase could be observed after the second impregnation processing. For the dielectric properties, the dielectric constant and loss had relatively stable value under different frequencies; however, the dielectric constants of the five composites did not change with the resin content regularly.

\section{Acknowledgements}

This research was funded by the National High Technology Research and Development Program of China (No. 2007AA03Z101), the State Key Program of National Natural Science of China (No. 51035003), the China Natural Science Foundation (Grant No. 50803010), the Shanghai Natural Science Foundation (Grant No. 12ZR1440500 and 14ZR1400100), the Doctoral Scientific Fund Project of the Ministry of Education of China (Grant No. 20120075120016) and the Fundamental Research Funds for the Central Universities.

\section{References}

[1] Sheng, D., Wang, H., Ying, Z., Wang, H.T. and Ying, Z.H. (2013) Application of Thermoplastic Polyimide Composite in Aerospace Field. Plastics, 42, 46-48.

[2] Xu, H.Y., Yang, H.X., Tao, L.M., Liu, J.G., Fan, L. and Yang, S.Y. (2010) Preparation and Properties of Glass ClothReinforced Meltable Thermoplastic Polyimide Composites for Microelectronic Packaging Substrates. High Performance Polymers, 22, 581-597. http://dx.doi.org/10.1177/0954008309354609

[3] Yu, L. and Cheng, X. (2013) Tensile Property of Surface-Treated Poly-p-phenylenebenzobisoxazole (PBO) Fiber-Reinforced Thermoplastic Polyimide Composite. Journal of Thermoplastic Composite Materials, 26, 307-321. http://dx.doi.org/10.1177/0892705711423290

[4] Li, J. and Cheng, X.H. (2007) Effect of Rare Earth Solution on Mechanical and Tribological Properties of Carbon Fiber Reinforced Thermoplastic Polyimide Composite. Tribology Letters, 25, 207-214. http://dx.doi.org/10.1007/s11249-006-9168-7

[5] Li, J. and Cheng, X.H. (2008) Evaluation of Tribological Performance of Surface-Treated Carbon Fiber-Reinforced Thermoplastic Polyimide Composite. Journal of Applied Polymer Science, 107, 1147-1153. http://dx.doi.org/10.1002/app.26639

[6] Paplham, W.P., Seferis, J.C., Calleja, F.J.B. and Zachmann, H.G. (1995) Microhardness of Carbon-Fiber-Reinforced Epoxy and Thermoplastic Polyimide Composites. Polymer Composites, 16, 424-428. http://dx.doi.org/10.1002/pc.750160512

[7] Rodeffer, C.D., Maybach, A.P. and Ogale, A.A. (1996) Influence of Thermal Aging on the Transverse Tensile Creep Response of a Carbon Fiber Thermoplastic Polyimide Composite. Journal of Advanced Materials, 27, 46-51.

[8] Pankow, M., Quabili, A. and Yen, C.-F. (2014) Hybrid Three-Dimensional (3-D) Woven Thick Composite Architectures in Bending. Journal of Materials Science, 66, 255-260. http://dx.doi.org/10.1007/s11837-013-0825-7

[9] Sun, B., Zhang, R., Zhang, Q., Gideon, R. and Gu, B. (2013) Drop-Weight Impact Damage of Three-Dimensional AngleInterlock Woven Composites. Journal of Composite Materials, 47, 2193-2209. http://dx.doi.org/10.1177/0021998312454904

[10] Udatha, P., Kumar, C.V.S., Nair, N.S. and Naik, N.K. (2012) High Velocity Impact performance of Three-Dimensional Woven Composites. Journal of Strain Analysis for Engineering Design, 47, 419-431. http://dx.doi.org/10.1177/0309324712448578

[11] Yao, L., Wang, X., Liang, F., Wu, R., Hu, B., Feng, Y., et al. (2008) Modeling and Experimental Verification of Di- 
electric Constants for Three-Dimensional Woven Composites. Composites Science and Technology, 68, 1794-1799. http://dx.doi.org/10.1016/j.compscitech.2008.01.014

[12] Callus, P.J., Mouritz, A.P., Bannister, M.K. and Leong, K.H. (1999) Tensile Properties and Failure Mechanisms of 3D Woven GRP Composites. Composites Part A: Applied Science and Manufacturing, 30, 1277-1287. http://dx.doi.org/10.1016/S1359-835X(99)00033-0

[13] Cox, B.N., Dadkhah, M.S. and Morris, W.L. (1996) On the Tensile Failure of 3D Woven Composites. Composites Part A: Applied Science and Manufacturing, 27, 447-458. http://dx.doi.org/10.1016/1359-835X(95)00053-5

[14] Qiu, Y.P., Xu, W., Wang, Y.J., Zikry, M.A. and Mohamed, M.H. (2001) Fabrication and Characterization of ThreeDimensional Cellular-Matrix Composites Reinforced with Woven Carbon Fabric. Composites Science and Technology, 61, 2425-2435. http://dx.doi.org/10.1016/S0266-3538(01)00164-6

[15] Tan, P., Tong, L.Y., Steven, G.P. and Ishikawa, T. (2000) Behavior of 3D Orthogonal Woven CFRP Composites. Part I. Experimental Investigation. Composites Part A: Applied Science and Manufacturing, 31, 259-271. http://dx.doi.org/10.1016/S1359-835X(99)00070-6

[16] Czigany, T. (2005) Basalt Fiber Reinforced Hybrid Polymer Composites. Materials Science Forum, 473-474, 59-66. http://dx.doi.org/10.4028/www.scientific.net/MSF.473-474.59

[17] Subagia, I.D.G.A., Kim, Y., Tijing, L.D., Kim, C.S. and Shon, H.K. (2014) Effect of Stacking Sequence on the Flexural Properties of Hybrid Composites Reinforced with Carbon and Basalt Fibers. Composites Part B: Engineering, 58, 251-258. http://dx.doi.org/10.1016/j.compositesb.2013.10.027

[18] Wang, J., Chen, B., Liu, N., Han, G. and Yan, F. (2014) Combined Effects of Fiber/Matrix Interface and Water Absorption on the Tribological Behaviors of Water-Lubricated Polytetrafluoroethylene-Based Composites Reinforced with Carbon and Basalt Fibers. Composites Part A: Applied Science and Manufacturing, 59, 85-92. http://dx.doi.org/10.1016/j.compositesa.2014.01.004

[19] Yao, L., Li, W.B., Wang, N., Li, W., Guo, X. and Qiu, Y.P. (2007) Tensile, Impact and Dielectric Properties of Three Dimensional Orthogonal Aramid/Glass Fiber Hybrid Composites. Journal of Materials Science, 42, 6494-6500. http://dx.doi.org/10.1007/s10853-007-1534-9 